\title{
Climate change: the challenges for public health and environmental effects in UAE
}

\author{
A. Salam \\ Department of Geography \& Urban Planning, UAE University, UAE
}

\begin{abstract}
The prevalence of diseases and other threats to human health depend largely on local climate. Extreme temperatures can lead directly to loss of life, while climaterelated disturbances in ecological systems, such as changes in the range of infective parasites, can indirectly impact the incidence of serious infectious diseases. Extreme climate changes surpassing their usual statistical ranges and tumbling records could be an early warning sign of global warming. Global warming poses serious challenges to the health sector as well as the environment and hence warrants emergency health preparedness and response. Thus, the main objective of this paper was to review health and environmental effects due to climate change in UAE. To conduct the review, the researchers had accessed different project reports, published articles and policy making papers related to climate change and its effect on health and environment. Climate sensitive diseases are among the largest global killers; hence the major brunt of global climate change in terms of adverse health impact will be mostly borne by poor and developing countries. These killer diseases are born due to ozone depletion, sea level rise, weather disasters, vector borne and marine disease, air pollution and heat effect. Some large-scale climate events have the potential to cause very large impacts. Both short and long term adaptation strategies in response to national and international weather change are needed that will be rife with challenges. It is concluded that an immediate challenge is to build the capacity needed to handle climate variability. Therefore this study recommends that a true preventive strategy needs to ensure the maintenance and development of healthy environments. In the long term, sustainable development and protection of ecosystem services are fundamentally necessary for human health.
\end{abstract}

Keywords: climate change, health, food insecurity, water supply, weather disasters. 


\section{Introduction}

Climate will always change due to the natural forcing of eccentricity. Climate changes occurring over time scales shorter than those associated with the orbital forcing frequencies are defined as short term. Climate fluctuations on time scales of less than 100 years are usually considered as climate variability. There is new and stronger evidence that most of the warming observed over the last 50 years is attributable to human activities (United Nation's intergovernmental panel on climate change (IPCC [1])). It was concluded that overall climate change is projected to increase threats to human health, particularly in lower income populations, predominantly within tropical/subtropical countries. Climate change is the biggest threat to nature and humanity in the 21 st century.

The health of the people depends on the stability and functioning of the earth's ecological and physical systems. Normally we ignore these life support systems mostly at a time when the society is gradually attracting towards urbanization and distanced from these natural systems. The climate system is an essential part of the life-supporting processes that are now coming under pressure due to population increase and economic activities thus global climate change is a significant addition to the environmental health hazards faced by humanity.

Today we start seeing impacts of climate change appearing in many places around the globe, for example, melting glaciers, rising sea levels, stronger storms, higher floods, less snow in the north and more drought in the south. Africa is one of the most vulnerable regions in the world to climate change. Change challenges were highlighted in Climate Change 2001, the Third Assessment Report of the Intergovernmental Panel on Climate Change (IPCC [1]). The report established how human activity (burning fossil fuels and changes in land-use) is modifying the global climate, with temperature rises projected for the next 100 years that could affect human welfare and the environment.

The Earth's surface has warmed by more than $0.8^{\circ} \mathrm{C}$ over the past century and by approximately $0.6^{\circ} \mathrm{C}$ in the past three decades (NASA [2]). This warming has been linked to more extreme weather conditions and is largely caused by human activities, mainly the burning of fossil fuels releasing carbon dioxide $\left(\mathrm{CO}_{2}\right)$ that traps heat within the atmosphere. These $\mathrm{CO}_{2}$ emissions continue to rise, and climate models project the average surface temperature will rise by $1.1^{\circ} \mathrm{C}$ to $6.4^{\circ} \mathrm{C}$ over the 21 st century (Change [3]).

Water vapour, carbon dioxide, ozone, methane and nitrous oxide trap solar energy in much the same way as the glass panels of a green house or a closed automobile. This natural greenhouse gases effect has kept the earth's atmosphere some $30^{\circ} \mathrm{C}$ hotter than it would otherwise be, making it possible for humans and other living things to exist on earth.

Human activities, however, are now raising the concentrations of these gases in the atmosphere and thus increasing their ability to trap energy. Carbon dioxide levels have risen from $280 \mathrm{ppm}$ by volume since before the industrial revolution to about $360 \mathrm{ppm}$ by 1990 (IPCC [4]). Man-made carbon dioxide which, is the most important contributor to the enhanced greenhouse gases effect, comes mainly from the use of coal, oil and natural gas. It is also released by the destruction of 
forests and other natural sinks and reservoirs that absorb carbon dioxide from the air.

The global greenhouse gas emissions due to anthropogenic activities have increased since pre-industrial times with increase of about $70 \%$ between 1970 and 2004 (IPCC [1]). The IPCC [1] also reports that the atmospheric concentrations of carbon dioxide (397 ppm) and methane (1744 ppb) in year 2005 exceed by far the natural range over the last 650,000 years. Fossil fuel use is the major contributor of global carbon dioxide, followed with land-use change. The major effect of the increase of anthropogenic greenhouse gas emissions in the atmosphere is global warming. It has been established that the climate change in the next 100 years will be due to anthropogenic activities (IPCC [1]). It has also been reported that 19952006 are the warmest years in the history of instrumentation (since 1850) and the global surface temperature rise is attributed to the greenhouse gases effect (IPCC [1]).

According to the IPCC [1], if countries around the world do not reduce emissions of greenhouse gases by the end of this century:

- Temperature globally is expected to increase by $7.4^{\circ} \mathrm{C}$, depending on population and economic growth.

- Global average sea level has risen since 1961 at a rate of $1.8 \mathrm{~mm}$ per year and since 1993 at $3.1 \mathrm{~mm}$ per year with contributions from thermal expansion, melting glaciers and ice-caps, and the polar ice sheets. Therefore, using the current rate, the sea level is expected to rise to $31 \mathrm{~cm}$ by the end of the century.

- Mortality and illness will have risen as the intensity and duration of heat waves increased and as the tropical habitat of mosquitoes that carry malaria and fever crept northward.

- Precipitation has increased significantly in eastern parts of north and South America, northern Europe and northern and central Asia but declined in the Sahel, the Mediterranean, southern Africa and parts of southern Asia. In summary precipitation is expected to increase in high latitudes and decrease in most subtropical land regions. This will significantly reduce food crop yields in developing countries as a whole.

- $\quad$ The frequency of extreme events (droughts, heat waves, cyclones, floods) is expected to increase. In north Atlantic an increase in intense tropical cyclone activity has been observed since 1970. Heat waves have become more frequent over most land areas and the frequency of heavy precipitation and thus floods has increased over most areas.

Greenhouse gases are now accumulating in the atmosphere at unprecedented rates. The annual growth rate of carbon dioxide $\left(\mathrm{CO}_{2}\right)$ concentration was highest over the last 10 years since the beginning of continuous direct atmospheric measurements (IPCC [5]). Over the next century, this warming trend, and changes in precipitation patterns, are expected to continue and be accompanied by a rise in sea level and increased frequency of extreme weather events. Thus, the main objective of this paper was to review health and environmental effects due to climate change in UAE. 


\section{Method and material}

The United Arab Emirates is situated in Middle East/southwest Asia, bordering the Gulf of Oman and the Persian Gulf, between Oman and Saudi Arabia; it is on a strategic location along northern approaches to the Strait of Hormuz, a vital transit point for world crude oil. The UAE lies between $22^{\circ} 50^{\prime}$ and $26^{\circ}$ north latitude and between $51^{\circ}$ and $56^{\circ} 25^{\prime}$ east longitude (Malit Jr. and Youha [6]). The total area of the UAE is approximately 83,600 square kilometres. In 2013, the UAE's total population was 9.2 million, of which 1.4 million are Emirati citizens and 7.8 million are expatriates, the majority of whom are Indian (Wikipedia [7]).

The researchers had accessed different project reports, published articles and policy making papers related with climate change and its effect on health and environment. A brief overview of likely health effects due to climate change is discussed in this paper.

\section{Changing climate in UAE}

The region of UAE has a dry subtropical type of weather with year-round sunny days, and rare and shallow rainfall. The type of weather is hot and moist along the shoreline and burning, and dehydrated in the interiors. The summers from the month of June to September are burning and moist, with temperatures touching $48^{\circ} \mathrm{C}\left(118^{\circ} \mathrm{F}\right)$ and dampness as high as $80-90 \%$. Dust laden sandstorms close by known as 'shaman' frequently hit the coast in midwinter and near the beginning of summer. Winter months (November to April) are gentle and enjoyable, with temperature averaging at $25^{\circ} \mathrm{C}\left(77^{\circ} \mathrm{F}\right)$ and humidity is lower (Emirates Travel [8]).

The consequence of the global warming will change the climate on the earth and the entire world has to suffer a huge crisis in terms of this huge change. The regions which are cold now, either fully or partly, will grow hotter and consequently the flora and fauna of that particular region will take major change, some of them will disappear over time. The people will lose their cultural identity and some new climatic condition will appear with less benefit to the people.

Greenhouse gases are now accumulating in the atmosphere at unprecedented rates. The annual growth rate of carbon dioxide $\left(\mathrm{CO}_{2}\right)$ concentration was highest over the last 10 years since the beginning of continuous direct atmospheric measurements (IPCC [5]). Carbon dioxide $\left(\mathrm{CO}_{2}\right)$, methane $\left(\mathrm{CH}_{4}\right)$, nitrous oxide $\left(\mathrm{N}_{2} \mathrm{O}\right)$ and fluorine compounds is the main contributor to the most greenhouse effect and burning of fossil fuels is the main cause of emissions of greenhouse gases.

According to the UAE embassy in Washington DC, the UAE's $\mathrm{CO}_{2}$ emissions increased from 60,809,000 tons in 1990 to 94,163,000 tons in 2002 and at the same time due to the transition to more natural gas in power plants, emissions of $\mathrm{CO}_{2}$ per capita have decreased. In 1990 the UAE produced 32.6 tons $\mathrm{CO}_{2}$ per person per year. In 2002 the figure had dropped to 25.1 tons per person per year, leaving the UAE as number four on the top emitter per capita global ranking list. The UAE is taking a number of steps to respond to this critical issue. Over the past decade action has been taken by many agencies and organisations in UAE to explore 
alternative means to check the exploitation of natural resources and its impact on environments and has drawn the world's attention for its efforts for sustainable development.

For example two world well-known research organizations Stockholm Environment Institute Sweden and Tufts University in the USA are hired to assess how rising levels of carbon dioxide in the atmosphere will affect the health of residents. In UAE Abu Dhabi National Oil Company (ADNOC) had a strategic objective to reduce flaring of natural gas and now has zero-flaring; Dubai is developing its master environmental plan that will ensure that growth and progress are achieved while protecting the environment, as well as Abu Dhabi which has also established the Masdar Initiative, one of the world's most comprehensive renewable and alternative energy programs.

\subsection{Impact on humans}

Change of weather and climate play a significant role in people's health and these changes would influence the functioning of many ecosystems and their member species as well as impacts on human health. These impacts of climate change on health will depend on many factors such as effectiveness of a society's health and safety systems to address the risk.

\subsubsection{Health}

The weather conditions have a direct impact on our health problems. It is anticipated that there will be an increase in the number of deaths due to greater occurrence and harshness of heat waves and other extreme weather events. The elderly, the very young and those suffering from respiratory and cardiovascular disorders will probably be affected by such weather extremes as they have lesser coping capacity.

An extreme rise in the temperature will affect people living in urban areas more than those in rural areas. This is due to the 'heat islands' that develop here owing to the presence of concrete constructions, paved and tarred roads. Higher temperatures in the cities would lead to an increase in the ground-level concentration of ozone thereby increasing air pollution problems. Indirectly, changes in weather pattern, can lead to ecological disturbances, changes in food production levels and an increase in the distribution of malaria, dengue and other vector-borne diseases (Patil and Deepa [9]). Fluctuation in the climate, especially in the temperature, precipitation and humidity can influence biological organisms and the processes linked to the spread of infectious diseases.

Climate change has critical health implications. Climate variability has had farreaching affects to human health, and includes, but is not limited to, the following: heat stress, air pollution, asthma, vector-borne diseases (malaria, dengue, schistosomiasis), tick borne diseases, water and food borne diseases. Changes in rainfall will affect the presence and absence of vector- and water-borne pathogens (IPCC [4]). For example, it can be expected that small changes in temperature and precipitation will boost the population of disease-carrying mosquitoes and result in increased malaria epidemics (Lindsay and Martens [10]). 
Due to the Siberian high pressure systems, above the ground pressure are supposed to be the main outside force system affects the weather conditions of the UAE and during the winter sometimes covering to the southern part of the Arabian land.

Even though the UAE has strong public health systems but climate change will still expected to affect many people. In addition, the impacts of climate change on public health around the globe could have important consequences for the people. Air quality in the UAE is generally good but the issue will probably need more attention as the development occurs. In general people should be more aware that some of their activities including the industrial activities which contribute to air pollution.

Particulate matter (PM) like tiny particles of sand, dust or chemicals is one pollutant that registers elevated levels. Nitrogen oxide, usually released in the combustion of fossil fuels, and ground-level ozone, or smog, which is formed when some chemicals released from human activities react with substances already in the atmosphere in the presence of sunlight, are two other substances that show elevated concentrations (Todorova [11]).

Reem Deed, a project manager for a Dubai based supplier of air-quality monitoring equipment and services, Environmental \& Industrial Solutions, also said that PM and ground-level ozone, especially in the summer, were the two pollutants most commonly registering high concentrations in Dubai.

In the capital, the Environment Agency Abu Dhabi (Ead) has also started detailed monitoring of particulate matter pollution, looking at levels of particles, known as PM10, which are only 10 micrometres in size, with a micrometre being a millionth of a metre (Todorova [11]).

Smaller particles such as PM2.5 which experts believe are particularly harmful as they are able to enter in the lungs. There are also concerns about secondary pollutants such as ozone and particulate matter which are substances that form in the atmosphere through reactions with primary pollutants. These particles are produced locally by the transport, mining and hydrocarbon manufacturing. Therefore, it is important to look these issues at regional level and not just the UAE.

The major brunt of global climate change in terms of adverse health impact will be mostly borne by poor and developing countries, even though rich and industrialized countries account for maximum greenhouse gas emission (Smith [12]).

\subsubsection{Biodiversity loss}

Biodiversity in the Gulf countries, is already worsening and it will be further damaged by intensifying climate change. Rapid population increase and development in the Gulf countries is challenging substantially on coastal marine life in the Arabian Gulf.

To limit further damage in the UAE, experts called for the expansion of protected marine areas along the UAE coastline. They also suggested a coordinated plan by all GCC countries to counter marine damage and streamline 
environmental stewardship into a unified approach to save remaining marine life areas (Sherif [13]).

Many plant and animal species in the Arab world already face threats to their survival, and their vulnerability will be exacerbated by the projected impacts of climate change. The number of species in the Arab world is already low by global standards, and the general harshness of the arid climate makes the region especially vulnerable to significant species los (Tolba and Saab [14]).

Coral reefs protect the coastline from erosion and inundation and are a focus for recreational activities such as diving and fishing. Compounds derived from coral reef organisms have even been used in pharmaceutical products, said Thabit Al Abdul Salam, director of the biodiversity management sector at Environment Agency Abu Dhabi, at the opening of the International Conference on Marine Life in the Arabian Gulf.

Economic prosperity, population growth, overfishing, and heavy commercial maritime shipping across the Arabian Gulf $20 \%$ of the world's oil passes through the Gulf daily has contributed to a potentially irreversible decline in the health of fragile coral reefs (Sherif [13]).

Coral reefs are the first ecosystem to have shown large scale impacts of climate change. A report by the United Nations University Institute for Water, Environment and Health shows that "the unprecedented scale of economic growth in the region and the significant development along the coastlines of many Gulf countries is putting pressure on coastal ecosystems". This has contributed to considerable degradation of natural habitats, including mangroves, sea grass beds, coral reefs and marine life (Sherif [13]). Large changes in ecosystem composition and function because of regional climate change would have cascading effects on species diversity (Solomon and Kirilenko [15]).

\subsubsection{Food security}

Increased climate variability already affects its water resources, land, forests, and biodiversity; and these impacts are likely to worsen over time. The estimate of rainfall in Morocco has declined by $30 \%$ in recent years and acreage is shrinking. Food security in the Arab world has long been subject to environmental and socioeconomic pressures. The dominant arid conditions, limited water resources, erratic cropping patterns, intensive grazing, population growth, and low knowledge and technology levels all affect food production systems in the region (Tolba and Saab [14]). A study in 2009 by Arab Forum found that 332 sq. $\mathrm{km}$ of the emirates of Ajman, Sharjah and Umm Al Quwain lie less than $10 \mathrm{~m}$ above sea level. This shows possible threat in case sea level increases because of the global warming in Arabian Gulf.

\subsubsection{Impacts on glaciers and water supply}

In 2007, the Northern Hemisphere reached a record low in ice coverage and the Northwest Passage was opened. At that point, we were told melting was occurring faster than expected, and we needed to accelerate our efforts. The gradual yet dramatic disappearance of glaciers on Mount Kilimanjaro is a result of global warming (IPCC [4]). An estimated $82 \%$ of the icecap that crowned the mountain when it was first thoroughly surveyed in 1912 is now gone. According to recent 
projections, if recession continues at the present rate, the majority of the glaciers on Mount Kilimanjaro could vanish in the next 15 years.

High temperatures are expected to increase evaporation losses, and Arab worlds are already in critical situation of water scarcity and its impact will reach severe levels by 2025. The major impact of climate change and variability on the water sector of the Gulf region will be through the changes in the hydrological cycle, the balance of temperature, and the rainfall. To tackle the water problem, Abu Dhabi has set up a groundwater monitoring system and is recycling by irrigating lawns and desert forests with residual waste. It has also started a public awareness campaign. Over the past 50 years the average temperature on the earth has risen at the fastest rate in recorded history with the hottest years on record occurring since 1990 (Zabarenko [16]).

The Arab region's coastal zones are of immense importance. The total length of the coastal zone in the Arab region is $34,000 \mathrm{~km}$, of which $18,000 \mathrm{~km}$ is inhabited. Most of the region's major cities and economic activity is in the coastal zones. Individual Arab countries will be affected differently under various climate change related sea level rise projections. Qatar, the UAE, Kuwait, and Tunisia are most vulnerable in terms of their land mass: $1-3 \%$ of land in these countries will be affected by a $1 \mathrm{~m}$ SLR (Tolba and Saab [14]).

Efforts to reduce overuse of natural resources recently won the UAE recognition on the World Environmental Performance Index (EPI) as the cleanest place in the GCC. The EPI is a biennial survey, carried out by the prestigious Yale University in collaboration with Columbia University, and it ranks countries from across the world based on 22 performance indicators in 10 policy categories. This year, only 132 countries made the cut, with Switzerland topping the chart (Kazmi [17]).

Experts have called for closer cooperation across the Arabian region to reduce the impact of climate change. The UAE has launched a number of initiatives such as a green building council, a massive afforestation programme, and development of Masdar the world's first zero-carbon, zero-waste, and car-free city in Abu Dhabi. Even with these efforts, there is still need for a comprehensive policy framework at the national level (Kazmi [17]).

\section{Conclusions}

Climate change is developing as a great threat that exactly demands an effective guideline and extensive policy as well as public attention. Over the years human societies have changed local ecosystems and modified regional climates. Climate change will have significant impacts on biodiversity and food security in Gulf countries. An immediate challenge is to build the capacity needed to handle climate variability. Therefore, substantial reductions of heat-trapping gas emissions in developed countries and adaptation strategies are crucial. For example, biodiversity must be managed to ensure that conservation is occurring both inside and outside of parks and reserves, and that adequate habitat is preserved to enable species, plants, animals and humans to migrate. The conservation of biodiversity will ensure delivery of ecosystem goods and services 
necessary to human life support systems (soil health, water, air, etc.). An integrated approach to environmental management is needed to ensure sustainable benefits for Gulf countries.

\section{Recommendations}

Environmental degradation is tied with human activities and setting up a framework within which local governments, research bodies and industries that contribute to pollution coordinate their efforts to share information.

Achieving cleaner environment for the UAE would also require regional cooperation to make sure other countries also better understand their responsibilities and contributions.

\section{References}

[1] IPCC. Special Report on Emissions Scenarios; Nakicenovic, N and Swart, R. (eds.) Cambridge University Press 2007.

[2] NASA Surface Temperature Analysis: Analysis Graphs and Plots. NASA: Goddard Institute for Space Studies 2007. http://data.giss.nasa.gov/ gistemp/graphs/ 24/12/2014.

[3] Change, C. The physical science basis: summary for policymakers. Geneva: Intergovernmental Panel on Climate Change secretariat 2007.

[4] IPCC. Climate Change 2001: Impacts, Adaptation and Vulnerability. IPCC Working Group II, Third Assessment Report. McCarthy, J.J., O.F. Canziani, N.A. Leary, UK; Cambridge University Press 2001.

[5] IPCC Climate change: The Physical Science Basis. Summary for Policy Makers In: Solomon S, Qin D, Manning M, Chen Z, Marquis M, Averyt KB, Tignor M, HL Editors Contributing of Working Group 1 to the Fourth Assessment Report of the Intergovernmental Panel on Climate Change Report UK; Cambridge University Press 2007a.

[6] Froilan T. Malit Jr., Ali Al Youha, Labor Migration in the United Arab Emirates: Challenges and Responses 2013 http://www.migrationpolicy.org/ article/labor-migration-united-arab-emirates-challenges-and-responses $12 / 02 / 2015$.

[7] Wikipedia Geography of the United Arab Emirates 2015 http://en.wikipedia.org/wiki/Geography_of_the_United_Arab_Emirates 12/02/2015.

[8] Emirates Travel UAE weather \& climate 2014 http://emiratesvoyage.com/ uae-guide/uae-weather-climate/ 24/12/2004.

[9] Patil, R. R., \& Deepa, T. M Climate change: The challenges for public health preparedness and response- An Indian case study 2007, Dept. of Health, UNDP, UN-House-II, Orissa, India 2007 http://www.ijoem.com/ article. 17/05/2010.

[10] Lindsay, S.W. \& Martens, W.J.M. malaria in the African highlands: past, present and future. Bulletin of the World Health Organization, 76:33-45. Macdonald, D. (ed.) The Encyclopaedia of Mammals Equinox Press 1998. 
[11] Todorova, V Experts call for careful eye to be kept on UAE air pollution levels, The National UAE 2014 on line http://www.thenational.ae/uae/ environment/experts-call-for-careful-eye-to-be-kept-on-uae-air-pollutionlevels 25/12/2014.

[12] Smith, A. Africa: up in smoke? The second report from the working group on climate change and development, new economics foundation, London 2006.

[13] Sherif I. Marine biodiversity under threat, Gulf News 2012 http:/gulfnews.com/news/gulf/uae/environment/marine-biodiversity-under -threat-1.968361 24/12/2014.

[14] Tolba, M. K \& Saab, N. W. impact of climate change on Arab countries in Tolba and Saab (edit) Arab Environment: Climate Change; Impact of Climate Change in Arab Countries, 2009 Report of the Arab Forum for Environment and Development 2009.

[15] Solomon, A.M. and Kirilenko, A.P. Climate change and terrestrial biomes: what if trees do not migrate? Global ecology and biogeography 6: 139-148. 1997.

[16] Zabarenko, A. Agent based social stimulation: A method for assessing the impact of seasonal climate forecast applications among smallholder farmers. Agric.sys. 83, 1-26. 2005.

[17] Kazmi, A. A chance to change the world, Gulfnews.com online (2012) http://gulfnews.com/news/gulf/uae/weather/a-chance-to-change-the-world$1.100889711 / 02 / 2015$. 